\section{WHAT A SCORCHER}

Between June and August 2010, extremely high temperatures (brown) hit about $13 \%$ of Earth's surface, an area roughly ten times greater than in 1951-80.

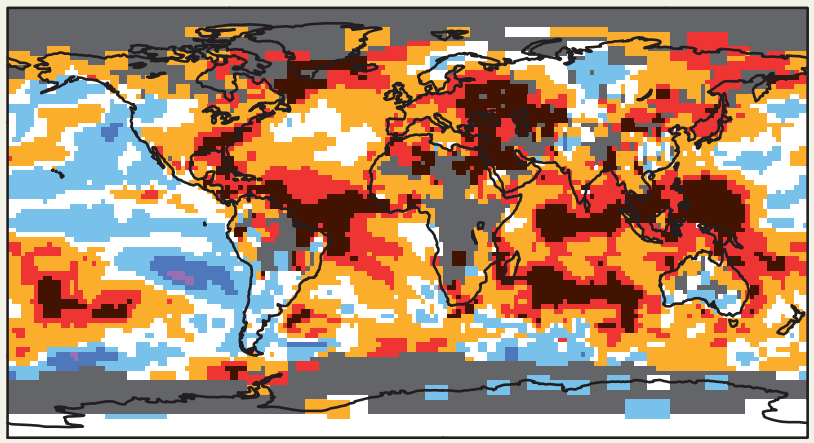

team of researchers investigate the physical mechanisms that drove some extreme weather events in 2010. Using a climate model developed at the NCAR, the team investigated links between a pair of El Niño and La Niña events (in which warm or cold surface waters, respectively, built up in the eastern Pacific Ocean) and weather events such as stronger monsoons in Asia and droughts in Russia and the Amazon. Although he thinks that global warming could have a role in such extreme events, Trenberth says that climate models have not yet been able to tease out the details.

"Models have a hard time doing extremes well," Trenberth says. But because of limited data sets for extreme weather and inadequate climate models, he worries that some people could draw the wrong conclusion: "that there is no human influence".

1. Hansen, J., Sato, M. \& Ruedy, R. Proc. Natl Acad. Sci. USA http://dx.doi.org/10.1073/pnas.1205276109 (2012).

2. Hansen, J. E. The Washington Post (5 August 2012).

3. Schiermeier, Q. Nature 477, 148-149 (2011).

4. Leiserowitz, A., Maibach, E., Roser-Renouf, C. \& Hmielowski, J. Global Warming's Six Americas, March 2012 \& Nov. 2011 (Yale Univ. \& George Mason Univ, 2012)

5. Dole, R. et al. Geophys. Res. Lett. 38, L06702 (2011)

6. Trenberth, K. E. \& Fasullo, J. J. Geophys. Res.

http://dx.doi.org/10.1029/2012JD018020 (in the press).

\title{
AWARDS
}

Physics prize
dwarfs all others

\section{Theorists left reeling after billionaire reveals massive prize.}

\section{BY GEOFF BRUMFIEL}

$\mathrm{W}$

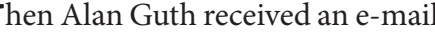
from a colleague asking if he could discuss a new annual prize in physics, he recalls, "I thought I was being asked to be on an organizing committee".

Instead, the other physicist, Nima ArkaniHamed at the Institute for Advanced Study in Princeton, New Jersey, told Guth that they were among the winners of a US\$3-million award. Guth, a theorist at the Massachusetts Institute of Technology in Cambridge who introduced the idea of cosmic 'inflation', assumed that the prize would be split. But Arkani-Hamed surprised him again: they had won $\$ 3$ million each. "Do you mean that I just won $\$ 3$ million and that you just won $\$ 3$ million?" Guth asked, incredulously. "He said 'yes"”

"At that point I just kind of fell off my seat," Guth says.

Last week's public announcement of the prize, which was awarded to nine physicists, was just as sudden (see go.nature.com/ mwaays). On 31 July, two weeks after Guth's unexpected conversation, stories appeared in The New York Times and The Guardian unveiling the \$27-million Fundamental Physics
Prize, which dwarfs all other prizes in science. Shortly afterwards, a bare-bones website appeared. Under the heading 'board', it listed just two people: Steven Weinberg, a Nobelprizewinning theorist at the University of Texas at Austin, and a man named Yuri Milner.

It was Milner, a 50-year-old Russian Internet entrepreneur, who founded the prize and chose the first winners (Weinberg was appointed to the board only after Guth and the others were notified). In his youth, Milner spent a decade studying theoretical physics in the Soviet Union before abandoning his $\mathrm{PhD}$ to move into the private sector. His early investments included a macaroni factory and a Russian e-mail portal, but Milner's fortune was sealed in 2009 when his firm bought a \$200-million stake in the social-media site Facebook. In May, Facebook began trading publicly, and Milner's company made an estimated $\$ 1.7$ billion. Today, his investment funds are valued at $\$ 12$ billion, and his personal wealth at around $\$ 1$ billion.

Milner never forgot his early years working on quantum chromodynamics, a theoretical framework that describes the interactions of quarks and gluons. For years he had toyed with the idea of creating a prize and, in recent months, he decided to act on it, choosing nine theorists who have never won Nobel prizes, but whose work he considers to be groundbreaking. "It was clear that he'd done a lot of homework," Arkani-Hamed says. "He knew an impressive amount about what was going on."

"The intention was to say that science is as important as shares trading on Wall Street," Milner told Nature. The prize money comes with no strings attached, although Milner hopes that the theorists will contribute to a new lecture series for the public. Milner also plans to create an annual \$100,000 New Horizons prize for young researchers and an ad hoc version of the Fundamental Physics Prize that can be won at any time "in exceptional cases", the website says. According to the rules of the prizes, anyone can be nominated, and future prizewinners will be selected by a committee of all previous ones.

"He's recognizing that there are some very smart people who have done some very clever things," says George Smoot, a physicist at the University of Paris Diderot who shared the 2006 Nobel Prize in Physics. But, he adds, giving such a large prize to top theorists, many of whom are late in their career, will not revolutionize theoretical physics. Smoot, who donated his portion of the Nobel prize to charity, says that he would have liked to have seen Milner put half of the \$27 million into fellowships for young researchers. Arkani-Hamed says that Milner is aware of the criticisms but felt that other philanthropists have created fellowships and institutes, and he wanted the new prize to stand apart.

For his part, Guth says that he hasn't yet decided what to do with the money, which was deposited directly into his bank account while he and his wife were away at a local Shakespeare festival. "We're still kind of in shock," he says. 